\title{
PENINGKATAN PENGETAHUAN SISWA SEKOLAH DASAR TENTANG DAMPAK GAME ONLINE
}

\author{
Dwi Christina Rahayuningrum $^{1 *}$, Etri Yanti ${ }^{2}$, Ibul Mardiko ${ }^{3}$ \\ ${ }^{1,2,3}$ Sekolah Tinggi Ilmu Kesehatan Syedza Saintika \\ Email Korespondensi : dwichristina05@gmail.com
}

\begin{abstract}
ABSTRAK
Fenomena game online sangat mempengaruhi para pelajar menggunakan waktu yang seharusnya untuk belajar tapi digunakan untuk bermain game online. Sehingga dalam proses belajar mengajar siswa kurang konsentrasi dan menyebabkan turunnya prestasi belajar dan terganggunya kesehatan. Tujuan dari kegiatan ini meningkatkan pengetahuan siswa sekolah dasar mengenai dampak game online. Kegiatan ini dilakukan di Sekolah Dasar Negeri 26 Air Tawar Timur Padang. Kegiatan ini diawali dengan memberikan pertanyaan seputar pengetahuan siswa sekolah dasar mengenai dampak game online. Dilanjutkan dengan memberikan materi menggunakan power point dan memberikan leaflet. Semua siswa antusias dalam mengikuti kegiatan ini terlihat dari banyaknya pertanyaan yang mereka ajukan. Kegiatan ini efektif dilakukan dalam peningkatan pengetahuan siswa dimana terlihat adanya peningkatan siswa sebelum dan sesudah mendapatkan penyuluhan yang terlihat dari koesioner pre dan post test yaitu sebesar 17,03 point. Kegiatan ini merupakan langkah awal untuk meningkatkan pemahaman siswa mengenai dampak game online serta mengantisipasi terjadinya kecanduan game online pada siswa.
\end{abstract}

Kata Kunci: Pendidikan Kesehatan, Tingkat pengetahuan, Game Online, Siswa Sekolah Dasar

\begin{abstract}
The phenomenon of online games greatly influences students to use the time that should be for studying but used to play online games. So that in the teaching and learning process students lack concentration and cause decreased learning achievement and disruption of health. The purpose of this activity is to increase the knowledge of elementary school students about the impact of online games. This activity was carried out at the State Elementary School 26 Air Tawar Timur Padang. This activity begins with asking questions about elementary school students' knowledge about the impact of online games. Followed by providing material using power points and giving leaflets. All students were enthusiastic in participating in this activity as seen from the many questions they asked. This activity is effectively carried out in increasing student knowledge where there is an increase in students before and after receiving counseling as seen from the pre and post test questionnaire, which is 17.03 points. This activity is the first step to improve
\end{abstract}


students' understanding of the impact of online games and to anticipate addiction. online games in students.

Keywords: Health Education, Level of knowledge, Online Games, Elementary School Students

\section{PENDAHULUAN}

Pesatnya perkembangan dunia menuju modernisasi membuat teknologi yang semakin canggih. Permainan yang dahulu tradisional, kini sudah beralih menjadi serba elektronik. Permainan elektronik ini dapat dilakukan di dalam ruangan, sehingga tanpa mengharuskan keluar rumah untuk melakukannya. Game Online memilki dampak positif dan negatif. Namun yang lebih sering mendapat sorotan adalah sisi negatifnya. Menurut (Van Solingen et al., 2011), ada empat dampak permainan internet yakni terhadap kesehatan, kepribadian, pendidikan, keluarga dan masyarakat.

Game online pertama kali muncul kebanyakan adalah game-game simulasi perang ataupun pesawat yang dipakai untuk kepentingan militer yang akhirnya dilepas lalu dikomersialkan, game-game ini kemudian menginspirasi game-game yang lain muncul dan berkembang. Selain sebagai sarana hiburan game online berfungsi sebagai sarana sosialisasi. Game online mengajarkan sesuatu yang baru karena adanya frekuensi bermain yang sering. Dengan sering melihat dan bermain game online, maka seseorang akan meniru adegan di dalam game online tersebut. Penggunaan sarana hiburan antara lain game online secara berlebihan tentu membawa dampak yang negatif. Bagi remaja hal ini dapat berpengaruh terhadap perilaku remaja yang mengarah pada penyimpangan sosial yang berdampak negatif (Mimi, 2017). Banyak faktor yang menyebabkan anak-anak sekarang lebih cenderung memilih kegiatan refreshing bermain game online dibandingkan dengan anak dahulu yang lebih menyukai olahraga. Yang pertama, waktu yang sempit disela-sela jadwal harian yang padat memaksa mereka untuk memilih jenis refreshing yang cepat, mudah dan murah. Kedua, game online tidak tergantung pada kehadiran sejumlah teman, tidak seperti refreshing olah raga yang membutuhkan kehadiran teman dalam jumlah tertentu, karena bisa dilakukan satu orang saja yaitu diri sendiri (Setiawan, 2018).

Di Indonesia penggemar game online mencapai 6 juta orang yang kebanyakan adalah usia remaja atau sekitar $40 \%$ yang ternyata memberikan dampak negatif pada mereka yang tidak mampu untuk berhenti bermain. Sebanyak $64,45 \%$ remaja lakilaki dan 47,85 remaja perempuan yang berusia $12-22$ tahun yang bermain game online menyatakan mereka kecanduan terhadap game online (Putro \& Nurjanah, 2013)

Kota Padang juga sudah mulai berkembang yang namanya permainan melalui situs-situs yang berbasis online yang dimana salah satunya adalah Game Online. Game online tidak berdampak terhadap kalangan para remaja saja, tapi sudah mulai meramba ke mahasiswa bahkan siswa/pelajar khususnya di Kota Padang. Hasil dari Dinas Pendidikan Kota Padang menyatakan bahwa umumnya pelajar yang berada dikota padang khususnya yang sekolahnya dekat dengan warnet maupun keluarga yang menengah ke atas yang sering anaknya menggunakan hp orang tuanya sering 
melakukan / bermain video game online tersebut. Prevalensi ini menunjukkan bahwa permainan game online khususnya di kota Padang juga dapat memepengaruhi siswa sekolah dasar (Dinas Pendidikan Kota padang, 2018).

Motivasi bermain game online akan menimbulkan efek adiktif, setiap orang memilki dorongan dan alasan yang berbeda untuk bermain game online. Dorongan dan alasan yang berbeda akan menimbulkan motivasi bermain game online (Yee, 2007). Anak- anak yang termotivasi bermain game online akan terus memainkan game online yang akan berdampak kepada aktivitas otak anak- anak yaitu kerusakan otak dibagian prefrontal cortex (PFC) sehingga anak- anak akan menjadi kurang dapat berkonsentrasi dalam berbagai hal, menimbang benar atau salah, berkurangnya kemampuan dan pengetahuan mengambil keputusan (Grant dan Potenza, 2006). Penelitian (Rahayuningrum et al., 2019) yang berjudul Hubungan motivasi bermain Game Online dengan adiksi Game online pada remaja, diperoleh nilai $p=0.000(p<0.05)$ maka dapat disimpulkan bahwa ada hubungan yang bermakna antara motivasi bermain game online dengan adiksi game online.

\section{MASALAH}

SDN 26 Air Tawar Timur merupakan salah satu Sekolah Dasar Negeri dengan Akreditasi A yang berada di Air Tawar Timur Kota Padang, status kepemilikan milik sendiri, memiliki 6 ruang kelas, pustaka, UKS dengan jumlah siswa 236 orang, jumlah murid laki-laki adalah sebanyak 97 siswa dan murid perempuan 138 siswa.

Alasan pemilihan SDN 26 Air Tawar Timur Padang sebagai tempat pengabdian kesehatan masyarakat berdasarkan hasil wawancara pada studi pendahuluan sekitar 80 \% siswa bermain game online, siswa mengatakan mereka sering sangat bermain game dirumah dengan menggunakan $\mathrm{Hp}$ yang dipinjam dari kakak dan orang tuanya, guru mengatakan bahwa banyak siswa sulit berkonsentrasi dalam belajar, prestasi belajar anak menurun. Oleh sebab itu perlu untuk dilakukan pendidikan kesehatan bertujuan untuk memberikan pendidikan pada siswa sekolah dasar mengenai pengertian game online, dampak positif dan negative game online, dampak game online terhadap aktivitas otak di Sekolah Dasar Negeri 26 Air Tawar Padang.

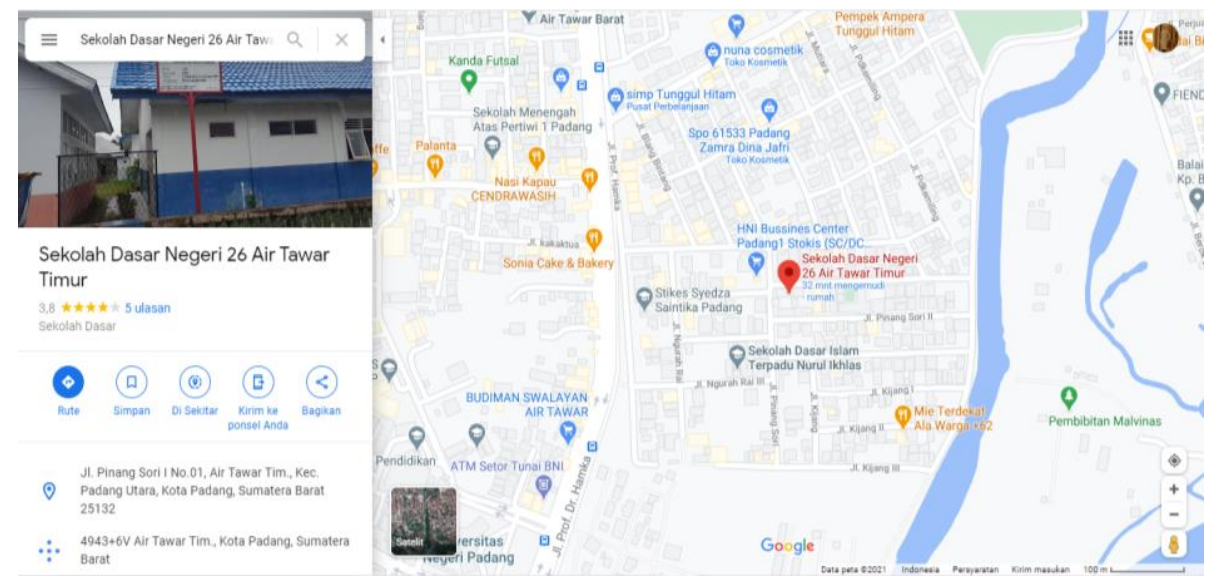

Gambar 2.1 Peta Lokasi SDN 26 Air Tawar Timur Padang

\section{METODE}


a. Tahap persiapan dari kegiatan adalah pembuatan pre planing, mengajukan ijin dan persiapan tempat dan alat - alat lainnya disiapkan oleh pihak SDN 26 Air Tawat Timur Padang. Pembuatan power point dan leaflet leaflat dimulai 2 hari sebelum kegiatan penyuluhan dimulai.

b. Tahap Pelaksanaan Acara ini dengan pemberitahuan kepada siswa dan siswi SDN 26 Air Tawar Timur Padang oleh salah satu pihak pengurus sekolah tersebut. Kegiatan ini dilakukan dengan metode penyuluhan. Sebelum dimulai penyuluhan, terlebih dahulu menyampaikan maksud dan tujuan kedatangan pelaksanaan penyuluhan, dibuka dengan pretest, dilanjutkan dengan penyampaian materi juga diskusi yang terarah berupa edukasi dan penyuluhan. Dalam penyuluhan ini pemateri akan memberikan leaflet yang berisikan materi dampak game online bagi siswa dengan tujuan agar siswa sekolah dasar dapat memahami dampak dari game online dan mengantisipasi terjadinya adiksi game online pada siswa.

c. Evaluasi

1. Struktur Peserta hadir sebanyak 31 orang siswa. Setting tempat sudah sesuai dengan rencana yang dibuat dan perlengkapan yang dilakukan untuk penyuluhan sudah tersedia dan sudah digunakan sebagaiman mestinya. Penyampaian materi menggunakan bahasa yang mudah dimengerti oleh siswa. Dalam penyampaiannya, siswa dapat memahami materi yang sudah disampaikan dan selama berjalannya penyuluhan dilakukan diskusi serta Tanya jawab untuk menarik minat siswa.

2. Proses Pelaksanaan kegiatan pukul $09.00 \mathrm{~s} / \mathrm{d} 11.00$ wib. Sesuai dengan jadwal yang telah direncanakan

3. Hasil
a. Peserta dapat memahami dan mengerti pengertian game online
b. Peserta dapat memahami dan mengerti dampak negative bermain game online
c. Peserta dapat memahami dan mengerti dampak Game Online terhadap aktivitas otak.
d.

\section{HASIL DAN PEMBAHASAN}

Penyuluhan Tentang Peningkatan Pengetahuan Siswa Tentang Dampak Game Online di SDN 26 Air Tawar Timur Padangg berjalan dengan tertib dan lancar. Pengabdian kepada masyarakat berupa penyuluhan kesehatan tentang dampak game online sebagai upaya ubtuk meningkatkan pengetahuan siswa mengenai dampak negative game online sehingga dapat mengantisipasi agar siswa tidak menjadi adiksi terhadap game online. Sasaran kegiatan pengabdian masyarakat ini adalah siswa yang berada disekolah tersebut. Siswa yang hadir sebanyak 31 Orang. 
Pelaksanaan penyuluhan tersebut mendapatkan respon yang baik, hal ini terlihat dari antusias dan kesiapan mengikuti kegiatan dari peserta dengan daftar hadir tepat waktu di lokasi. Selain itu peserta tampak antusias ketika mengikuti jalannya kegiatan, sehingga terjadi tanya jawab dan diskusi yang baik antara pemberi penyuluhan dengan peserta penyuluhan. Mereka juga sangat senang ketika menerima pembagian leaflet yang bisa digunakan untuk dibaca kembali bila di perlukan.

Berikut gambar pelaksanaan penyuluhan:
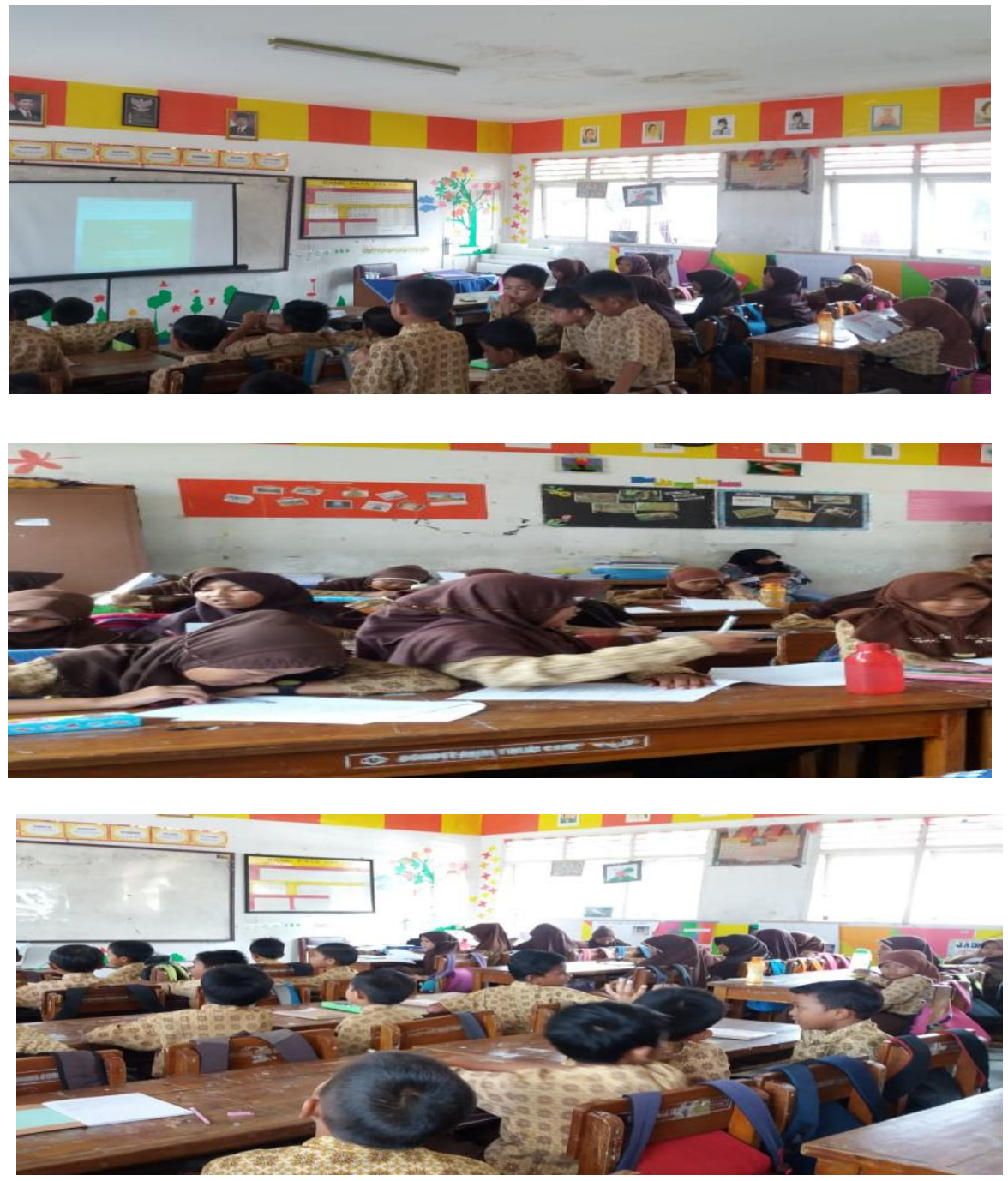

Gambar 4.1 Pelaksanaan Kegiatan Penyuluhan

\section{KESIMPULAN}


Dari hasil kegiatan Pengabdian Kepada Masyarakat tentang Dampak Game Online di SDN 26 Air Tawar Timur Padang, maka disimpulkan adanya peningkatan pengetahuan siswa tentang game online meliputi pengertian game online, dampak negative game online serta dampak dampak Game Online terhadap aktivitas otak

\section{DAFTAR PUSTAKA}

Adachi, P.J.C. dan Willoughby T. (2011). The Effect of Video Game Competition and Violence on Agresive Behavior: Which Characteristic Has the Greatest Influence?. Psychology of Violence. 1 (4), 259-274. doi: 10.1037/a0024908 (2012). Do Video Games Promote Positive Youth Development?. Journal of Adolescent Research, 28(2), 155-165. doi:10.1177/0743558412464522

Adams, E. \& Rollings, A. (2007). Fundamental of Game Design. Prentice Hall. Retrieved April 29, 2013, from http://www.designersnotebook.com/Books/Fundamentals_of_Game_Design Ifundamentals_ch21.pdf

Bowman, N.D., Weber, R., Tamborini, R., \& Sherry J. (2013). Facilitating Game Play: How Others Affect Performance at and Enjoyment of Video Games. Media Psychology, 16, 39-64. doi: 10.1080/15213269.2012.742360

Brunborg, G. S., Mentzoni, R. A., \&Frøyland, L. R. (2014). Is Video Gaming, or Video Game Addiction, Associated with Depression, Academic Achievement, Heavy Episodic Drinking, or Conduct Problems? Journal of Behavioral Addictions, 3(1), 27-32. doi:10.1556/JBA.3.2014.002

Mimi, U. (2017). Pengaruh Kecanduan Game Online terhadap Perilaku Remaja di Mabes Game Center jalan Hr. Subrantas Kecamatan Tampan Pekanbaru. Jom. FISIP.

Putro, T. A., \& Nurjanah, N. (2013). Perilaku Adiksi Pada Pemain Game Online Di Dinustech Semarang Dan Dampaknya Terhadap Kesehatan. Visikes.

Rahayuningrum, D. C., Putit, Z., \& Erwina, I. (2019). Hubungan Motivasi Bermain Game Online Dan Dukungan Sosial Teman Sebaya Dengan Adiksi Game Online Pada Remaja di SMPN Kota Padang. Jurnal Kesehatan Medika Saintika. https: / / doi.org/10.30633/jkms.v10i1.315

Setiawan, H. S. (2018). ANALISIS DAMPAK PENGARUH GAME MOBILE TERHADAP AKTIFITAS PERGAULAN SISWA SDN TANJUNG BARAT 07 JAKARTA. Faktor Exacta. https: / / doi.org/10.30998/faktorexacta.v11i2.2338

Van Solingen, R., Dullemond, K., \& Van Gameren, B. (2011). Evaluating the effectiveness of board game usage to teach GSE dynamics. Proceedings - 2011 6th IEEE International Conference on Global Software Engineering, ICGSE 2011. https://doi.org/10.1109/ICGSE.2011.24

Yee, N. (2007). Motivations for Play in Online Games. CyberPsychology \& Behavior. https://doi.org/10.1089/cpb.2006.9.772 